Research Article

\title{
Rotating Arm-Based Experimental Study on Droplet Behavior in the Shoulder Region of an Aircraft Aerodynamic Surface
}

\author{
S. Sor, ${ }^{1}$ A. García-Magariño, ${ }^{2}$ and A. Velazquez ${ }^{3}$ \\ ${ }^{1}$ National Institute of Aerospace Technology (INTA), 28850 Madrid, Spain \\ ${ }^{2}$ ISDEFE Engineering Systems for Spanish Defense, Beatriz de Bobadilla 3, 28040 Madrid, Spain \\ ${ }^{3}$ Aerospace Engineering, Fluid Mechanics and Aerospace Propulsion Department, Universidad Politécnica de Madrid, Plaza del \\ Cardenal Cisneros 3, 28040 Madrid, Spain
}

Correspondence should be addressed to A.Velazquez; angel.velazquez@upm.es

Received 29 May 2017; Accepted 12 September 2017; Published 26 October 2017

Academic Editor: Kenneth M. Sobel

Copyright (C) 2017 S. Sor et al. This is an open access article distributed under the Creative Commons Attribution License, which permits unrestricted use, distribution, and reproduction in any medium, provided the original work is properly cited.

An experimental study has been performed on water droplet deformation in the shoulder region of an airfoil. The experiments have been carried out in a rotating arm facility $2.2 \mathrm{~m}$ long and able to rotate up to $400 \mathrm{rpm}(90 \mathrm{~m} / \mathrm{s})$. A blunt airfoil model (chord length equal to $0.468 \mathrm{~m}$ ) was placed at the end of the arm. A droplet generator was used to generate a stream of water droplets with an initial diameter of $1000 \mu \mathrm{m}$. An imaging system was set up to record the trajectories and deformations of the droplets in three different regions close to the airfoil shoulder. The base flow field was characterized using a particle image velocimetry system. The experiments show that droplet deformation results in the shoulder region of the airfoil are different from those pertaining to the leading edge region. In particular, droplets in the shoulder region tend to rotate to the direction of the incoming airfoil which generates an interference effect between the droplets that make up the stream. These differences have been quantified applying an existing theoretical model specifically developed for the leading edge region to the results obtained in the present study.

\section{Introduction}

Droplet deformation is a subject of interest both from the basic fluid mechanics and from the aerospace engineering points of view. First, regarding fundamental fluid mechanics, one of the main challenges of droplet deformation and breakup research is to generalize the different modes of deformation. At the early stages of this type of research, the deformation modes were characterized based on qualitative features. More recently, different attempts have been tried to identify a limited set of fundamental mechanisms that manifest themselves in the fashion of a wide variety of different deformation modes. For a comprehensive review of this approach, the interested reader is directed to the work of Theofanous [1] and Theofanous and $\mathrm{Li}$ [2]. Another basic fluid mechanics aspect that has attracted the attention of researchers has been the influence that the flow velocity profile has on both the droplet deformation and breakup processes. Even though many theoretical and experimental studies (based, mostly, on shock-tube-type facilities) have been carried out in conditions of constant, or nearly constant, flow velocity, certain applications of engineering interest are characterized by either accelerating or decelerating flow profiles. In this specific area, the relevant references are the works of Temkin and Mehta [3], Igra and Takayama [4], and Jourdan et al. [5]. It is also important to refer to the advances made in this field using computational fluid mechanics techniques. Recently, Chang et al. [6] have presented a numerical method that solves the Navier-Stokes equations in computational domains containing a variable number of material interfaces for a wide range of flow parameters, thereby allowing for a large flexibility in the analysis of these problems. Rendall and Allen [7] have proposed a combined Lagrangian finite volume 
formulation that speeds up the convergence of the numerical algorithm. Jung and Myong [8] have presented a second-order finite volume scheme that allows for the problem solution without the need to resort to a parallel Lagrangian formulation. Computation of the problem using a one-way iteration approach that simplifies convergence (at the expense of losing accuracy) has been addressed by Iuliano et al. [9].

Second, with regard to aerospace engineering applications, the issue of droplet deformation and breakup has to do with two different aspects related to flight safety. The first one is the effect of heavy rain on flight controllability, while the second one is its influence on icing conditions. Statistics show [10] that about $50 \%$ of the accidents in civil aviation are connected to adverse atmospheric conditions. A large, not easily quantified, percentage of these accidents involved heavy rain [11]. The reason is that heavy rain impacts on the forward part of the fuselage and on the wings and, therefore, it affects the torque around the aircraft centre of gravity [10]. Also, droplet impact and accumulation on wings and control surfaces generate an "artificial roughness" effect that degrades controllability. For example, Hansman and Craig [12] have shown that rain with a water content of $30 \mathrm{gr} / \mathrm{m}^{3}$ degrades the aerodynamic behavior of NACA $64-210$ and NACA 0012 airfoils by a factor of $5 \%$ and 15\%, respectively. Heavy rain may also clog the gap in a lifting surface with deflected slats, thereby causing premature boundary layer separation [13]. Also, Rehorts et al. [14] have estimated that icing caused 542 flight accidents between 1976 and 1988. This is because ice accretion deteriorates aerodynamic performance by a factor of the order of $5 \%$ to $25 \%$ [15]. Additionally, icing may contribute to the anticipation of dynamic stall [16].

In this context of aerospace engineering applications, it is important to quantify the influence of these effects on the systems and products that industry designs and manufactures. Typically, up to now, this influence has been accounted for by means of using semiempirical correlations (see the references quoted in the previous paragraph). However, it would be interesting to move one step forward by means of increasing the level of fidelity of the methods and tools used by the industry. From a practical viewpoint, the authors of this article believe that it is likely that the next generation of industrial tools will be of a statistical nature. The reason is that, to be of practical use, they will have to account for the simultaneous behavior of larger numbers of droplets. For a generic and, also, in depth description of these methods, see the review article of Lasheras et al. [17]. Within this logic of development, it is relevant to refer to the article of Maab and Kraume [18] that uses single-drop experiments to determine the breakage rates that are needed in population balance equation (PBE) models. These PBE formulations are a class of very promising statistical-like methods thatare being used in this field. It is, also, interesting to quote, literally, what Maab and Kraume [18] write in the introduction section of their article: "the key challenge associated with the formulation of predictive PBE models is the experimental determination of unknown drop breakage and coalescence functions as sub-models in the PBE". That is, a possible way (among many others) to develop new methods and tools for the aeronautics industry could be the use of specific PBE formulations in which the required breakage functions are obtained via experiments, via models derived from the experiments, or via numerical simulations; see, for example, [19], for the numerical approach. Specifically, this is the train of thought that the authors of the present article are following.

In a previous study, the authors of this article, GarcíaMagariño et al. [20], carried out an experimental study on single-droplet deformation in the leading edge region (close to the stagnation streamline) of an airfoil. Details of the experimental setup as well as the data reduction techniques that were used are given in [21]. Based on those experimental data, Sor et al. [22] developed a theoretical model for single-drop trajectory and deformation. However, those studies were somewhat limited in the sense that to generate reliable prediction tools, knowledge on the phenomenon all around the airfoil is required. This is why the present study focuses, complementarily, on droplet deformation in the shoulder region of the airfoil. From the fluid mechanics point of view, the main difference with the case presented previously by GarcíaMagariño et al. [20] is that in the airfoil leading edge region, the flow, as seen from the droplet frame of reference, accelerates in the direction of the airfoil motion with no significant gradient in the direction normal to it. However, in the shoulder region, there are velocity gradients in the direction of the airfoil motion and also in the direction normal to it. As it will be shown in a later section, this fact causes a different sequence on the droplet deformation behavior. Finally, it is to be noted that the authors of this article were not able to find previously published experimental results on droplet deformation in the shoulder region of an airfoil; so, to the best of their knowledge, the present results might be the first to be available in the open literature.

Regarding article organization, the experimental setup is described in Section 2, results and the associate discussion are presented in Section 3, and finally, conclusions are stated in Section 4.

\section{Description of the Experimental Facility and Equipment}

This study was carried out at the rotating arm facility of INTA (Instituto Nacional de Técnica Aeroespacial-National Institute of Aerospace Technology) located in Madrid, Spain. The rotating arm has a length of $2.2 \mathrm{~m}$ and it is placed on top of a supporting structure. The rotating motor that propels the arm is located inside the support structure and has a power of $5 \mathrm{KW}$. These working conditions allow for a maximum translational velocity of $90 \mathrm{~m} / \mathrm{s}$ at the arm end (400 rpm). The rotational velocity is monitored using a led optical system that focuses a light beam on the rotating arm and monitors its reflection. The airfoil model, manufactured out of styrofoam, was located at the arm, and it had a chord length of $0.468 \mathrm{~m}$. Its leading edge radius was $0.070 \mathrm{~m}$ and 
TABLE 1: Dimensionless profile shape coordinates. " $c$ " stands for the chord length. The leading edge coordinates are as follows: $x / c=0, z / c=0$.

\begin{tabular}{lccc}
\hline$x / c$ & $z / c$ & $x / c$ & $z / c$ \\
\hline 1.000 & 0.000 & 0.241 & 0.200 \\
0.937 & 0.014 & 0.211 & 0.196 \\
0.877 & 0.028 & 0.183 & 0.191 \\
0.818 & 0.044 & 0.157 & 0.183 \\
0.762 & 0.059 & 0.133 & 0.173 \\
0.707 & 0.076 & 0.110 & 0.162 \\
0.655 & 0.093 & 0.090 & 0.150 \\
0.604 & 0.110 & 0.072 & 0.136 \\
0.556 & 0.127 & 0.056 & 0.121 \\
0.510 & 0.143 & 0.042 & 0.105 \\
0.465 & 0.158 & 0.030 & 0.089 \\
0.423 & 0.171 & 0.020 & 0.072 \\
0.383 & 0.183 & 0.012 & 0.055 \\
0.344 & 0.192 & 0.006 & 0.041 \\
0.308 & 0.198 & 0.002 & 0.032 \\
0.274 & 0.200 & 0.000 & 0.000 \\
\hline
\end{tabular}

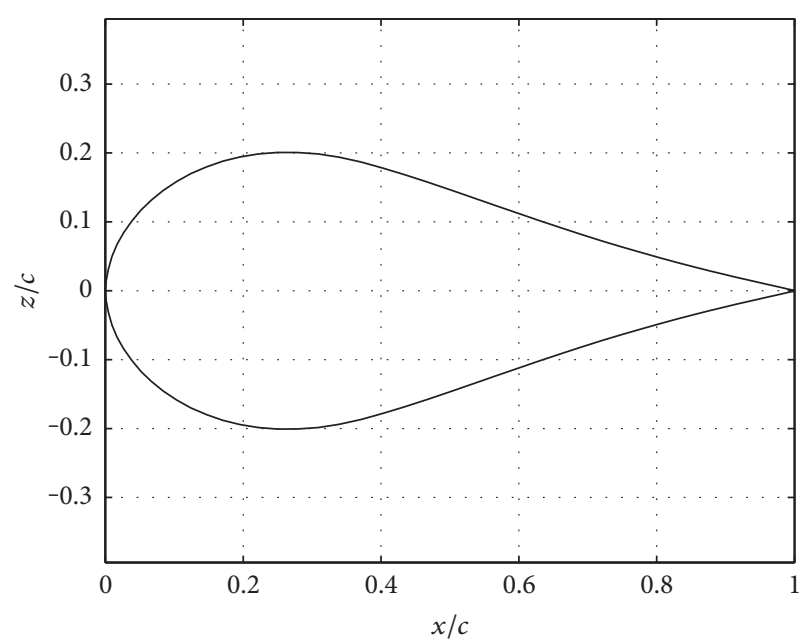

FIgure 1: Airfoil profile shape.

the thickness was $0.187 \mathrm{~m}$. The airfoil length was $0.2 \mathrm{~m}$ in the span-wise direction, with rounded tips. The dimensionless coordinates of the profile are given in Table 1, while its actual shape is presented in Figure 1.

As it could be observed, the chosen profile was rather blunt which is representative of a wide class of commercial aircraft airfoil shapes. The droplet generator was a monosized TSI MDG-100. Droplet diameters could be selected in the range from $300 \mu \mathrm{m}$ to $1500 \mu \mathrm{m}$. This was achieved by means of varying both the jet mass flow rate and the vibration frequency at the piezoelectric. The water discharge could be selected in the range from $2.2 \mathrm{~cm}^{3} / \mathrm{min}$ up to $51.79 \mathrm{~cm}^{3}$ / min. Vertical droplet velocities in the measurement window were of the order of $5 \mathrm{~m} / \mathrm{s}$ (the airfoil velocity varied between $50 \mathrm{~m} / \mathrm{s}$ and $90 \mathrm{~m} / \mathrm{s}$ ). The camera to record images was a

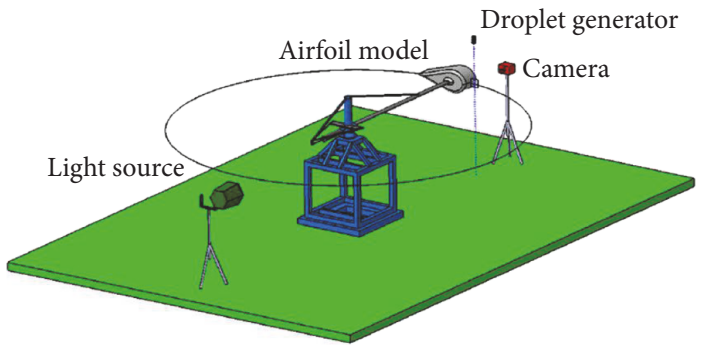

FIGURE 2: Sketch of the facility.

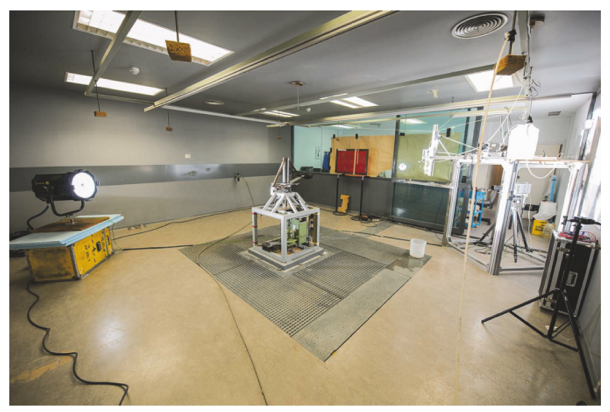

FIgURe 3: Actual view of the facility.

Photron SA-5. The capturing rate could be chosen in the range from 1000 frames per second (fps) up to $1,000,000 \mathrm{fps}$. The resolution was dependent of the capturing rate. For these experiments, the selected capturing rate was $72,000 \mathrm{fps}$ which led to an image resolution of $192 \times 512$ pixels. Shutter speed was $1 \mu \mathrm{s}$. The software used to capture and save the images was Photron FASTCAM, while the software used to analyze and process the image was SITEA [22], which was developed for this purpose in a Matlab environment. To improve capturing quality, the droplets were illuminated with $2000 \mathrm{~W}$ Xenon light to create a shadowgraph in a white gray background. A sketch of the experimental setup is shown in Figure 2, while an actual photograph of the facility is presented in Figure 3.

Analysis and postprocessing of the droplet deformation results required characterization of the flow field generated by the airfoil. This was done using a TSI particle image velocimetry (PIV) system. Two pulsed ND:Yag $190 \mathrm{~mJ}$ lasers were used for illumination purposes. Laser pulses lasted for $8 \mathrm{~ns}$ each. Images were recorded with a Power View Plus $4 \mathrm{MP}$ camera. Its resolution was $2048 \times 2048$ pixels. Camera lenses were AF-S VR Micro-Nikkor 80-200 mm f/2.8 D IF$\mathrm{ED}$ and Nikkor $50 \mathrm{~mm} \mathrm{f/1.4.} \mathrm{Flow} \mathrm{seeding} \mathrm{in} \mathrm{the} \mathrm{testing}$ room was performed using $1 \mu \mathrm{m}$ droplets. Image capturing and flow synchronization was achieved using the TSI Insight $3 \mathrm{G}$ software and a synchronizer. Sampling frequency of the flow field varied between $4.8 \mathrm{~Hz}$ and $6.5 \mathrm{~Hz}$. The time between two consecutives pulses was chosen between $1 \mu \mathrm{s}$ and $200 \mu \mathrm{s}$. At the most critical case, a particle would move of the order of $1 \mathrm{~mm}$ between pulses that is a distance much smaller than the problem characteristic length (the airfoil leading edge radius) that was $70 \mathrm{~mm}$. Every single PIV area was divided into smaller interrogation areas containing 


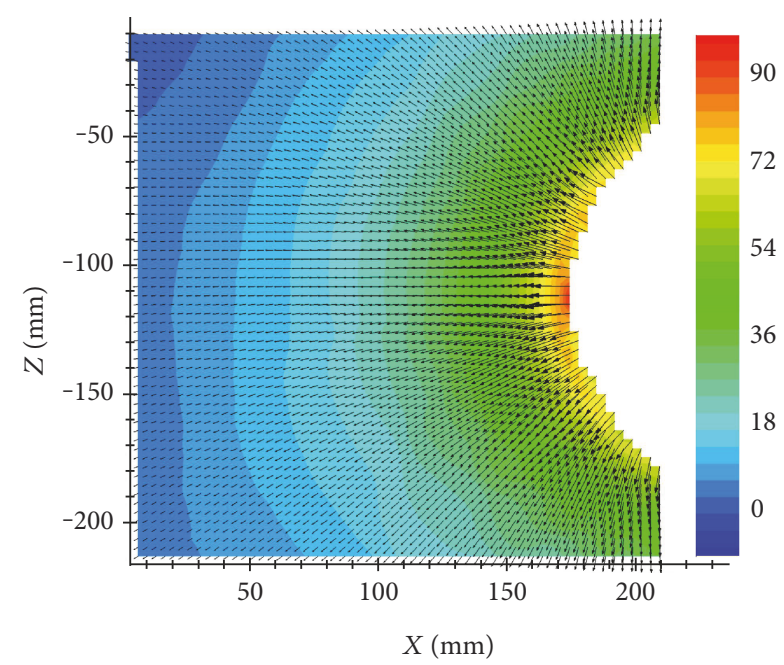

Figure 4: Average flow field velocity for the 50 measurements. The airfoil velocity was $90 \mathrm{~m} / \mathrm{s}$.

$64 \times 64$ pixels. It was assumed that the characteristic time of the problem was the characteristic time of the flow velocity variation (as seen from the droplet reference frame). This characteristic time was estimated as the ratio of a characteristic velocity to a characteristic acceleration. In the worstcase scenario, the time between pulses was about 15 times smaller than the characteristic time of the problem. Accordingly, it was considered that both the spatial and temporal resolution of the PIV system were appropriate to describe the problem under consideration. The flow characterization was carried out without the presence of droplets. So, in a sense, it was assumed a one-way interaction approach (see [9]). Figure 4 shows the 2D velocity map, in the airfoil reference frame, obtained for the airfoil velocity of $90 \mathrm{~m} / \mathrm{s}$. These results are the average of 50 different measurements. It could be argued that flow characterization could have been done far more easily using an analytical approach, for example, using the potential flow velocity profile past an airfoil. However, it was decided to do it experimentally because of three different facts: (a) the flow field was turbulent (the Reynolds number was in the range from 2,000,000 to 5,000,000), (b) the airfoil trajectory was circular (instead of rectilinear) in a closed room where the flow was continuously being disturbed, and (c) the airfoil was not two dimensional but, instead, it had a finite length in the span-wise direction.

With regard to repeatability, each case in the matrix of experimental cases to be described in the next section was repeated 50 times. It was found that dispersion of the results was larger in the cases with highest airfoil velocity. Figure 5 shows the 2D map of the standard deviation of the 50 measurements at the highest airfoil velocity. In this case, the spread was of the order of $\pm 3 \mathrm{~m} / \mathrm{s}$ that is much smaller than the airfoil velocity $(90 \mathrm{~m} / \mathrm{s})$.

\section{Description of the Experimental Cases}

Nine different cases were addressed in this experimental study. They corresponded to the variation of two parameters:

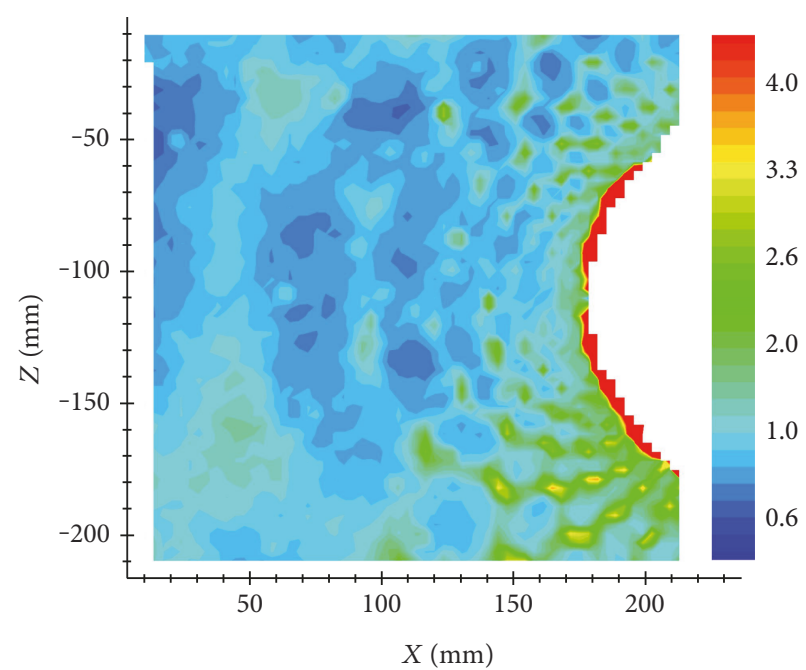

Figure 5: 2D map of the standard deviation of the 50 flow field measurements for airfoil velocity equal to $90 \mathrm{~m} / \mathrm{s}$.

(i) Parameter \#1: the velocity of the approaching airfoil. Three cases were considered: $50 \mathrm{~m} / \mathrm{s}, 70 \mathrm{~m} / \mathrm{s}$, and $90 \mathrm{~m} / \mathrm{s}$.

(ii) Parameter \#2: the position relative to the airfoil of the field of vision (FOV) where the droplet deformation was recorded. In particular, three different heights of the midline of the FOV with respect to the airfoil stagnation line were considered: FOV \#1: $38 \mathrm{~mm}$, FOV \#2: $58 \mathrm{~mm}$, and FOV 3: $66 \mathrm{~mm}$.

The initial droplet diameter (on the order of $1 \mathrm{~mm}$ ) and the airfoil model where unchanged through the experiments. To ensure repeatability, each of the nine experimental cases was repeated four times. To illustrate the area that was analyzed, the position of the three different FOV's is shown in Figure 6. A sketch of the typical results to be expected for each FOV is shown in Figure 7.

The key for the nine different cases is presented in Table 2.

\section{Experimental Results and Discussion}

From a quantitative point of view, each of the nine cases (\#1 to \#9) described in Table 2 is characterized by the slip velocity profile that the airfoil generates past the droplet. In particular, it is the unsteady loading associated to the velocity profile that causes the droplet deformation and eventual breakup that have been observed. The nine slip velocity profiles have been measured and the results are presented in Figures 8, 9, and 10 as a function of the horizontal distance to the airfoil leading edge. This slip velocity has been computed in two steps assuming a one-way interaction process, that is, the air velocity has been obtained via PIV while the droplet velocity has been measured with the optical camera tracking its horizontal position as a function of time. Regarding the repeatability of the results, Figure 11 shows the uncertainties associated 


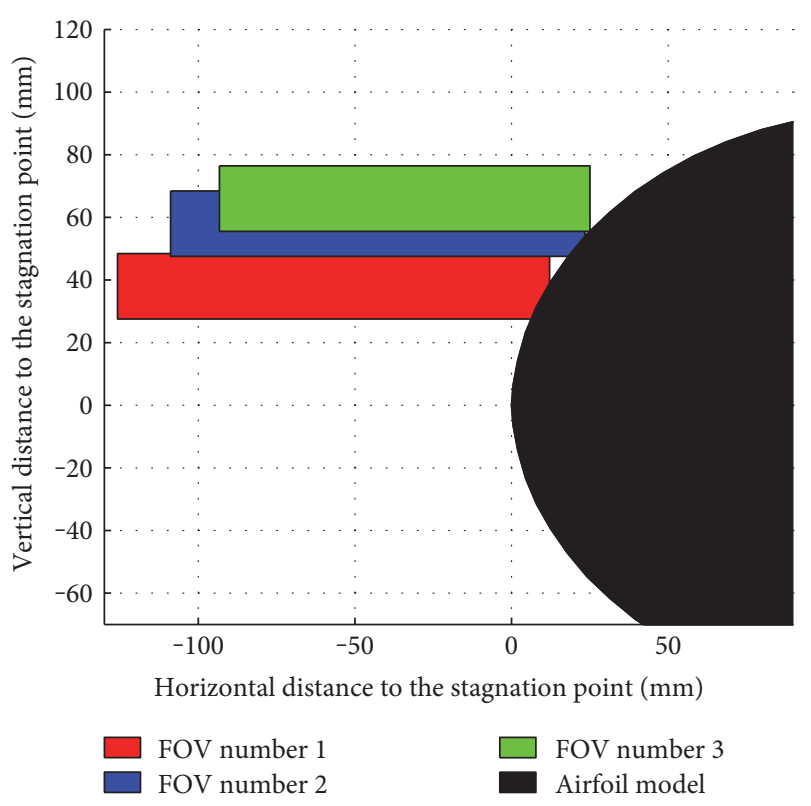

FIgURE 6: Location of the different FOV relative to the airfoil.

to 50 repetitions of case \#3 experiments. In particular, the different measured horizontal positions of the droplet are shown in this figure. It could be observed that the largest uncertainty, of the order of $\pm 5 \%$, occurs at times close to the finalization of the experimental series, that is, when both the air and droplet velocity are higher.

Looking, for example, at Figure 8, it could be observed that the slip velocity profile associated to FOV \#1 leads to slip velocities that are larger than those associated to FOV \#2. At the same time, slip velocities associated to FOV \#2 are larger than those corresponding to FOV \#3. The reason, see Figure 6, is that FOV \#1 is the closest one to the airfoil leading edge region, while FOV \#3 is the one located the farthest away from it. The same trend can also be observed in Figures 9 and 10. Also, when comparing, for example, Figures 8 and 9, it could be seen that slip velocities are larger in Figure 9 that correspond to an airfoil velocity of $70 \mathrm{~m} / \mathrm{s}$, than those presented in Figure 8 that correspond to an airfoil velocity of $50 \mathrm{~m} / \mathrm{s}$. The same behavior could be observed when comparing Figures 9 and 10. Now, the evolution of droplet deformation (quantified as the ratio of the largest to the smallest dimension of the droplet in the photographs) associated to the nine cases defined in Table 2 is presented in Figures 12, 13, and 14.

Figure 12 shows that in this case, that is characterized by the lowest airfoil velocity $(50 \mathrm{~m} / \mathrm{s})$, droplet deformation depends strongly on the specific FOV used. For example, the deformation associated to FOV \#3 is much smaller than deformation associated to FOV \#1. The reason is that, see Figure 8, slip velocities associated to case \#3 are consistently smaller than those associated to case \#1. It is also worth observing that the deformed droplets tilt in the direction of the incoming airfoil. In some cases, at the last measurement instants, this tilting is close to 45 degrees. It is also worth noting that the dark shape of the airfoil can be glimpsed in the

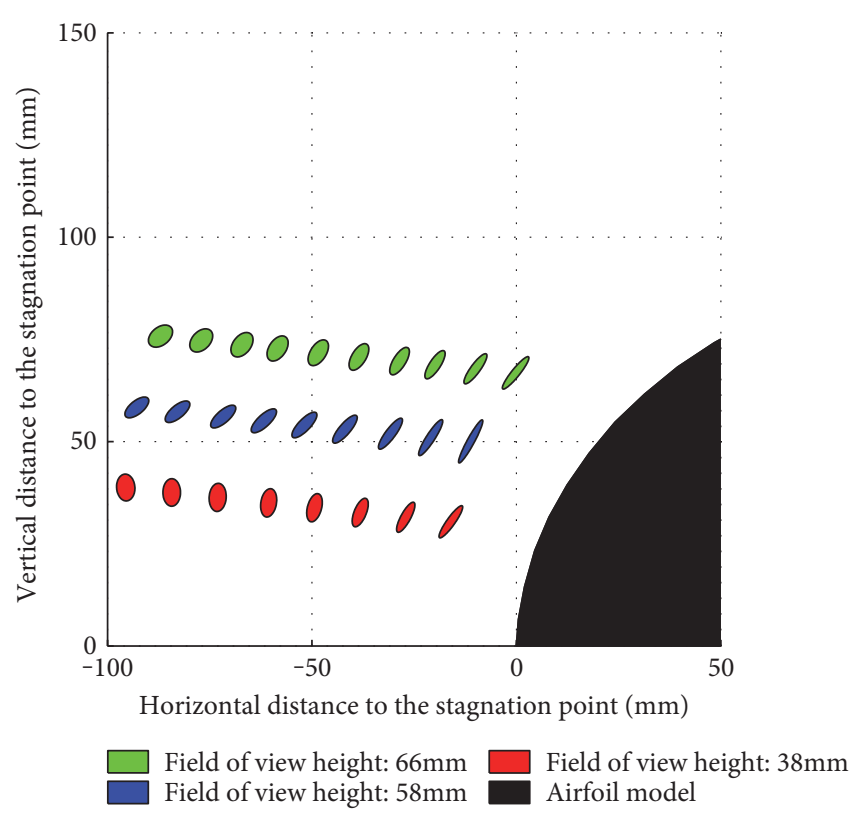

Figure 7: Sketch of the type of results to be expected relative to the airfoil.

TABLE 2: Key of the nine different experimental cases. $U_{m}$ stands for the airfoil velocity.

\begin{tabular}{lccc}
\hline Case key & FOV \#1 & FOV \#2 & FOV \#3 \\
\hline$U_{m}=50 \mathrm{~m} / \mathrm{s}$ & 1 & 2 & 3 \\
$U_{m}=70 \mathrm{~m} / \mathrm{s}$ & 4 & 5 & 6 \\
$U_{m}=90 \mathrm{~m} / \mathrm{s}$ & 7 & 8 & 9 \\
\hline
\end{tabular}

lowest frame (far-right corner) of the left column of Figure 12 . When the airfoil velocity increases up to $70 \mathrm{~m} / \mathrm{s}$, see Figure 13, all deformations, as well as the degree of tilting, tend to be similar for the three different FOVs. This observation is further reinforced when observing the results presented in Figure 14. The reason could be that above some threshold loading, all droplets tend to deform to the same asymptotic state. It is, nevertheless, worth noting that the local details of the deformation are different even if the global aspects are similar. This can be observed when comparing the right and left columns of Figure 13 and the right and left columns of Figure 14. In those cases, droplets existing in FOV \#3 tend to deform with concavity pointing towards the incoming airfoil, while the opposite happens for droplets recorded inside FOV \#1. This suggests that droplet deformation is apt to be analyzed in terms of both local and global patterns. Or to put in other words, a plausible theoretical model of model deformation might have two different scales: the local scale and the global scale. This also suggests that the breakup pattern may also be different in the different FOVs owing to the dissimilar deformation history.

Another aspect to be noted in the results presented in Figures 12,13 , and 14 is that the deformation of the train 


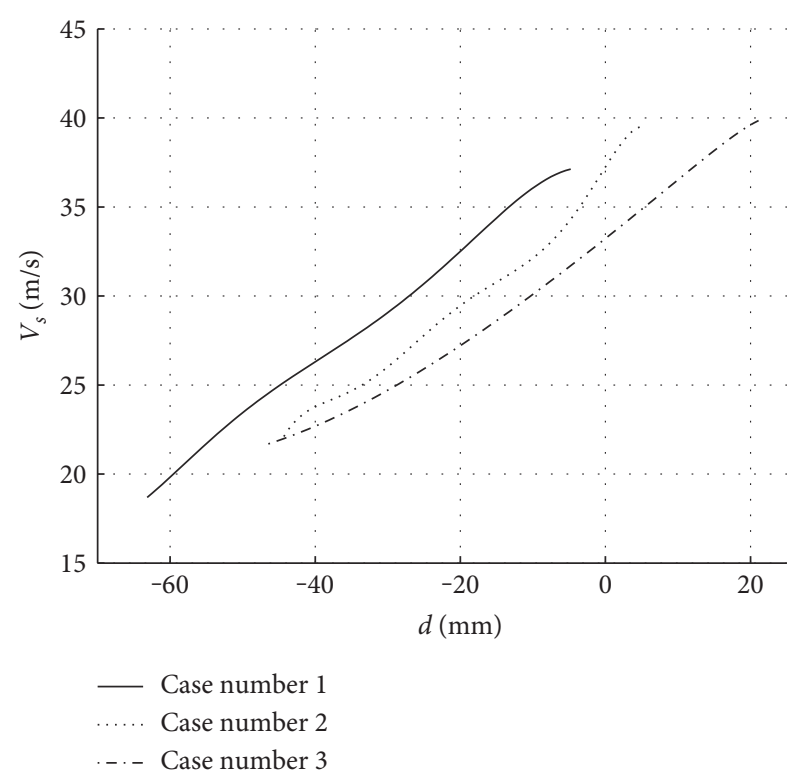

FIGURE 8: Slip velocity profiles for cases \#1, \#2, and \#3 as a function of the droplet horizontal distance to the airfoil leading edge.

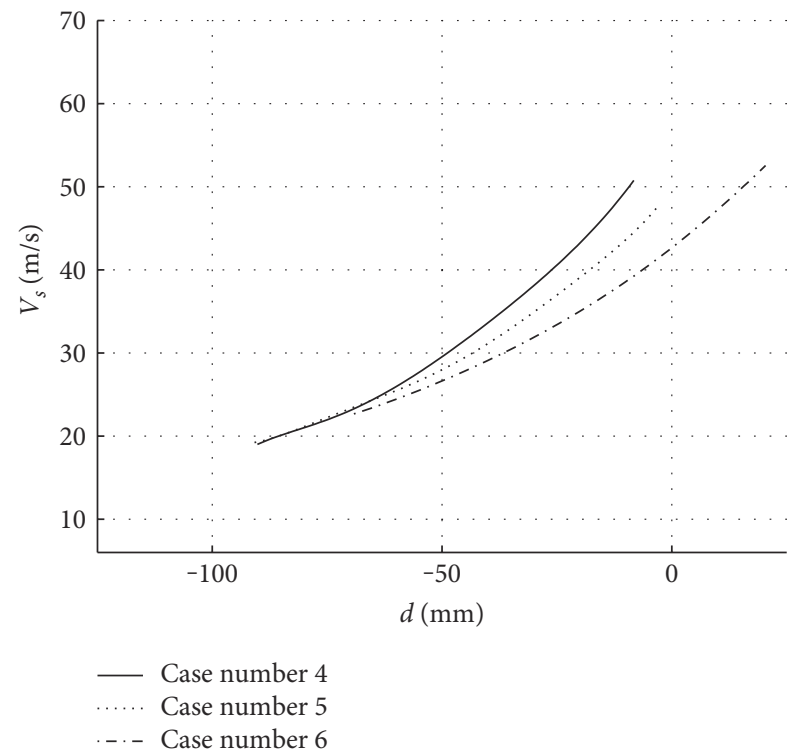

Figure 9: Slip velocity profiles for cases \#4, \#5, and \#6 as a function of the droplet horizontal distance to the airfoil leading edge.

of droplets causes aerodynamic interference between the droplets themselves. This is because of the abovementioned tilting towards the incoming airfoil that is in contrast with experimental results obtained for droplet trains focused on the leading edge region [20]. In the present case, the tilting suggests that the aerodynamics behavior of each single droplet is somewhat coupled to that of its nearest neighbors. To further quantify this effect, the slip velocity direction has been computed out of the experimental results and it is shown, superimposed in green color, in the train of droplets corresponding to case \#9; see Figure 15.

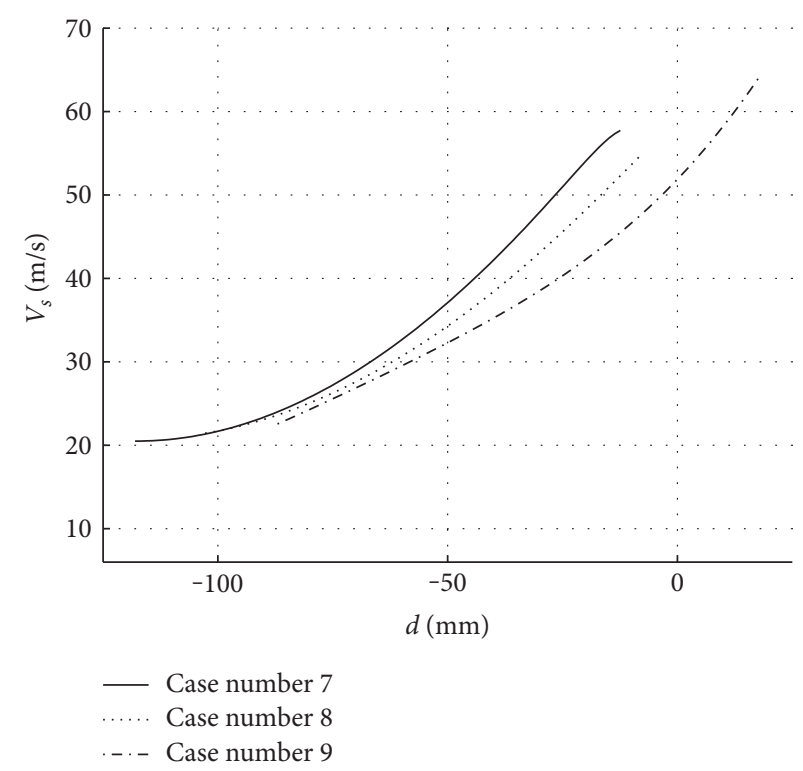

FIGURE 10: Slip velocity profiles for cases \#7, \#8, and \#9 as a function of the droplet horizontal distance to the airfoil leading edge.

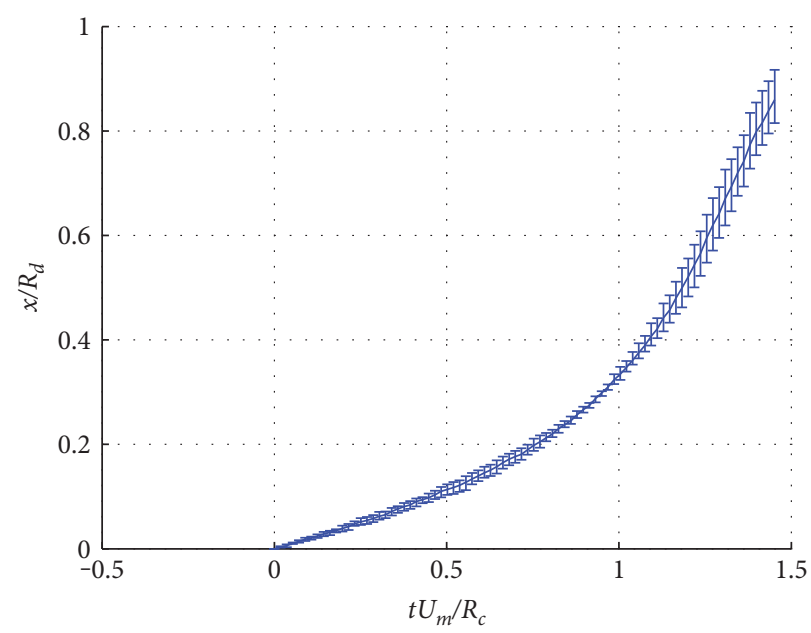

Figure 11: Experimental uncertainty associated to the different repetitions of case $\# 3$.

To observe this effect in more detail, the last snapshot of Figure 15 has been enlarged and it is shown in Figure 16. There, it could be observed that each single droplet is partly shielded by their downstream neighbor and possibly affected by its downstream recirculation region; so this fact actually affects the aerodynamics loading impinging on it. In any case, it is to be noted that the 2D picture of Figure 16 might give an exaggerated impression of the actual shielding. The reason is that in the actual 3D situation the fact that deformed droplets assume a disk like form causes the shielding to be smaller (this could have been observed if pictures in the direction perpendicular to that of Figure 15 could have been taken). In any case, all this suggests that, in the shoulder region of the airfoil, analytical models for droplet deformation should 

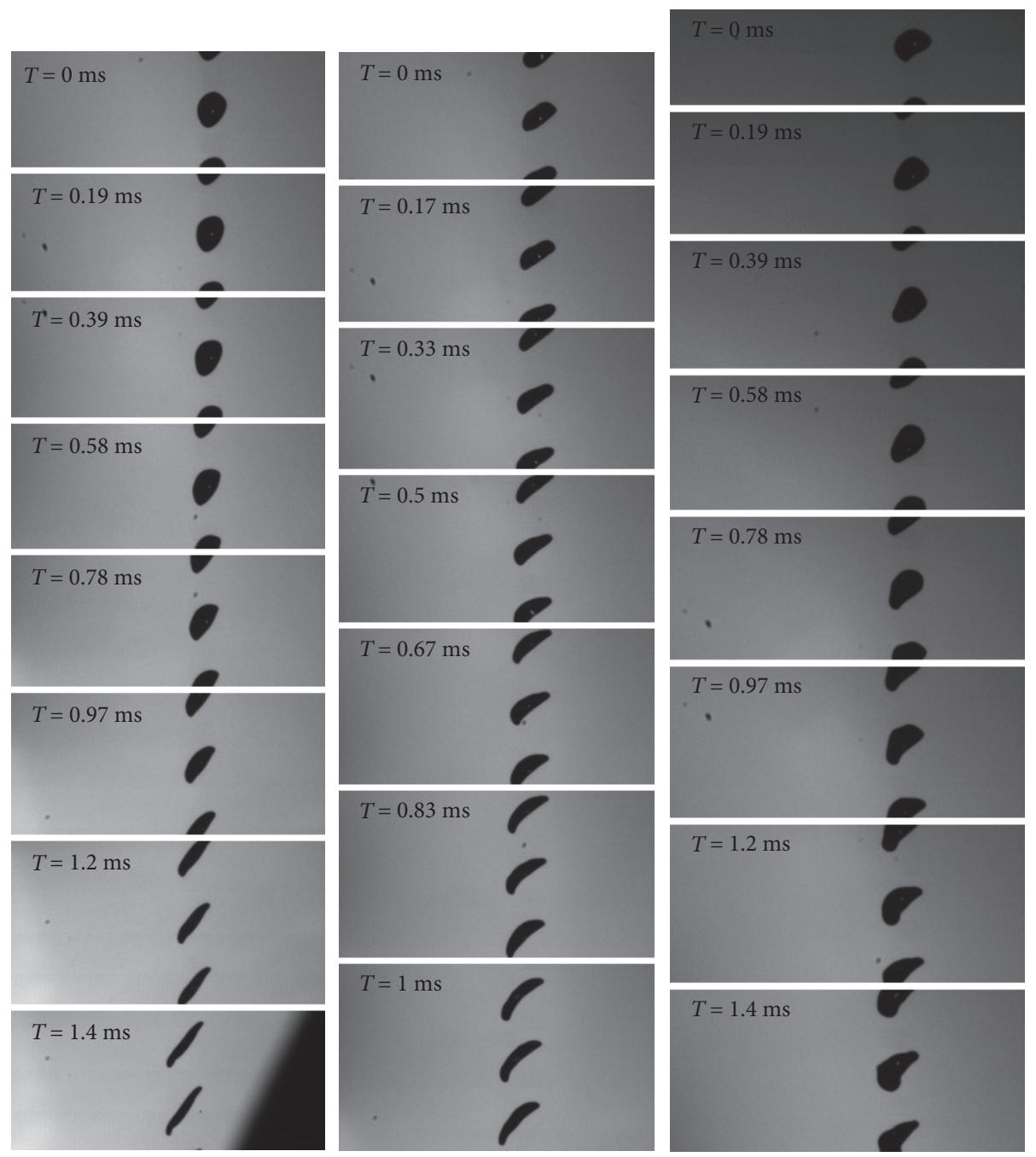

Figure 12: Recorded droplet evolution for cases \#1 (left), \#2 (centre), and \#3 (right).

not target isolated droplets but, instead, they should account for aerodynamic interferences. In practice, this means that the modeling complexity required for this region will probably be higher than that considered by Sor et al. [22] who focused on the leading edge region only. As a matter of illustration, Figure 17 shows the counterpart of Figure 15 but performing the measurements right in the leading edge region (neither FOV \#1, \#2, or \#3 but one additional dedicated set of measurements). In Figure 17, it could be observed that tilting, and the associated aerodynamic interference, is negligible in the airfoil leading edge region. On the other hand, in an actual in-flight situation, this aerodynamics interference depends on the liquid water content (LWC) of the cloud that the actual airfoil is immersed into. In heavy rainfall, LWC is of the order of $32 \mathrm{gr} / \mathrm{m}^{3}$ with droplet diameters around $6 \mathrm{~mm}$. These figures can go down to LWC of about $1 \mathrm{gr} / \mathrm{m}^{3}$ with droplet diameters of $1 \mathrm{~mm}$. However, the experimental setup used in this work dealt with trains of droplets, not with clouds of droplets. This means that interference effects in both situations are markedly different. For example, the separation between consecutive droplets in the experiment is smaller than the typical separation in the case of heavy rainfall (LWC of about $\left.32 \mathrm{gr} / \mathrm{m}^{3}\right)$.

Now, it is interesting to compute the trajectory and deformation of the droplets in the shoulder region, as shown above, using the model proposed by Sor et al. [22]. The model contains three ordinary differential equations: two dynamic equations for the horizontal and vertical droplet position and a third equation for droplet deformation. The actual form of the model equations computed is as follows:

$$
\begin{aligned}
m_{d} \frac{d^{2} x}{d t^{2}}= & \frac{1}{2} \rho_{\text {air }} V_{s} V_{s x} \pi a^{2} \\
& \cdot\left(C_{D_{\text {sphere }}}^{\left(R_{d} / a\right)^{3}} \cdot C_{D_{\text {disk }}}^{1-\left(R_{d} / a\right)^{3}}+k \frac{R_{d} / a^{2}}{V_{s}^{2}} \frac{d V_{s}}{d t}\right), \\
m_{d} \frac{d^{2} y}{d t^{2}}=- & \frac{1}{2} \rho_{\text {air }} V_{s} V_{s y} \pi a^{2} \\
& \cdot\left(C_{D_{\text {sphere }}}^{\left(R_{d} / a\right)^{3}} \cdot C_{D_{\text {disk }}}^{1-\left(R_{d} / a\right)^{3}}+k \frac{R_{d} / a^{2}}{V_{s}^{2}} \frac{d V_{s}}{d t}\right)+m_{d} g
\end{aligned}
$$



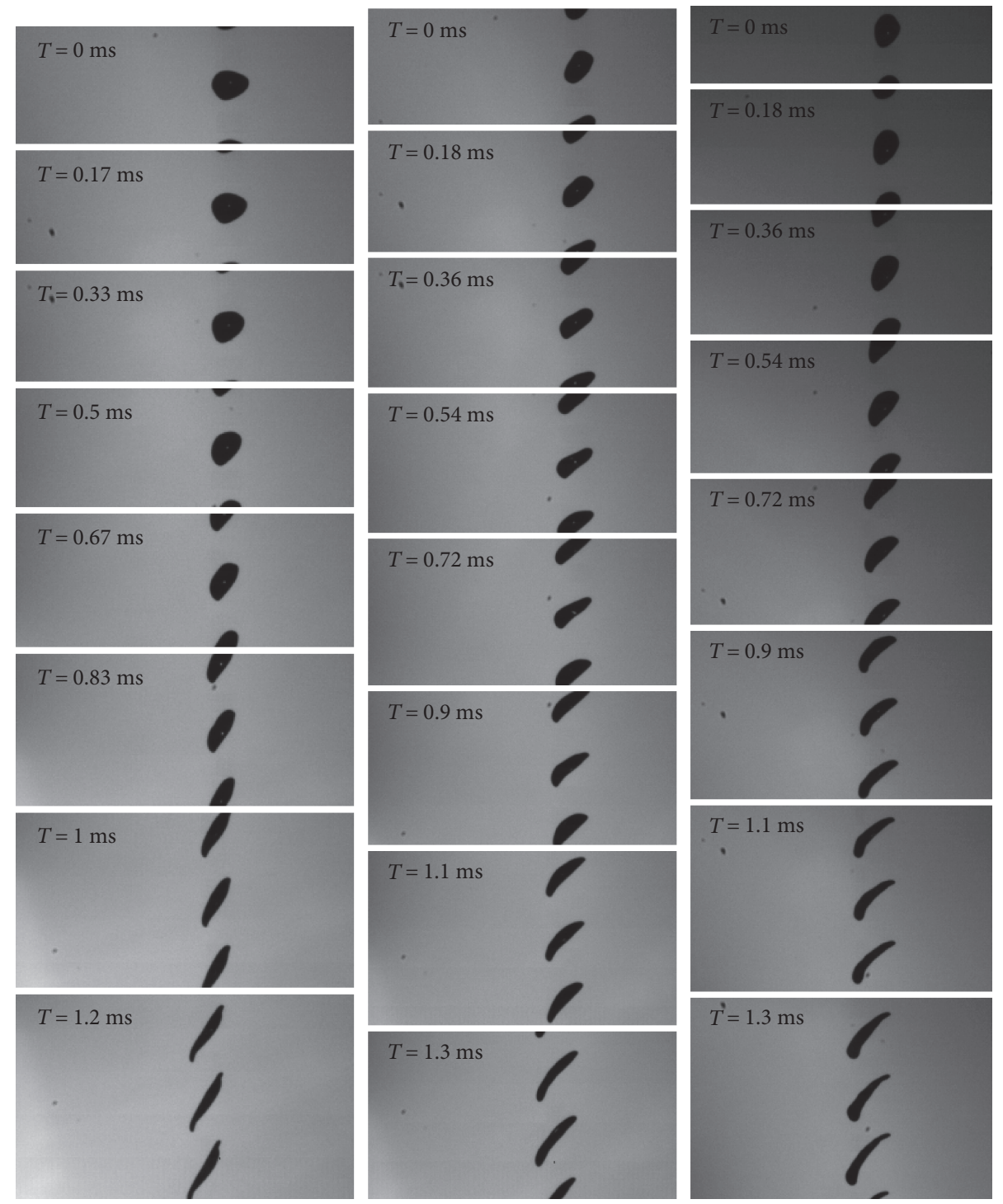

Figure 13: Recorded droplet evolution for cases \#4 (left), \#5 (centre), and \#6 (right).

$\frac{3 m_{d}}{16} \frac{d^{2} a}{d t^{2}}=-\frac{64}{9} \mu_{d} \pi R_{d}^{3} \frac{1}{a^{2}} \frac{d a}{d t}-\frac{4}{3} \sigma \frac{d A_{d}}{d a}+\frac{1}{2} C_{P} \rho_{\text {air }} V_{s}^{2} \pi R_{d}^{2}$,

where

$$
\begin{gathered}
\frac{d A_{d}}{d a}=4 \pi a-\frac{4 \pi R_{d}}{\varepsilon\left(a / R_{d}\right)^{5}} \ln \left(\frac{1+\varepsilon}{1-\varepsilon}\right) \\
+\frac{3 \pi R_{d}}{\varepsilon\left(a / R_{d}\right)^{11}}\left[\frac{2}{\varepsilon\left(1-\varepsilon^{2}\right)}-\frac{1}{\varepsilon} \ln \left(\frac{1+\varepsilon}{1-\varepsilon}\right)\right], \\
\varepsilon=\left[1-\left(\frac{R_{d}}{a}\right)^{6}\right]^{1 / 2} .
\end{gathered}
$$

$x, y$, and $a$ are the droplet horizontal and vertical displacements and the droplet maximum half diameter. The other parameters are described in the Nomenclature list. Slip velocities $V_{s x}, V_{s y}$, and $V_{s}$ that appear in (1), (2), and (3) are defined as follows:

$$
\begin{aligned}
& V_{s x}=V_{\mathrm{air}_{x}}-\frac{d x}{d t}, \\
& V_{s y}=V_{\text {air_y } y}-\frac{d y}{d t}, \\
& V_{s}=\sqrt{V_{s x}^{2}+V_{s y}^{2}} .
\end{aligned}
$$

The air velocity components, $V_{\text {air }_{x}}$ and $V_{\text {air_y } y}$, were measured using the PIV system as explained in Section 2. These components were measured as a function of the distance to the airfoil model that moved with constant velocity $U_{m}$. Then, $V_{\text {air }}, V_{\text {air_y }}$ were obtained as a function of the variables $x$ and $y$. It is interesting to note that the model presented by Sor et al. [22] is formally valid on the airfoil leading edge stagnation region only. In this region, the slip velocity in the vertical direction could be 

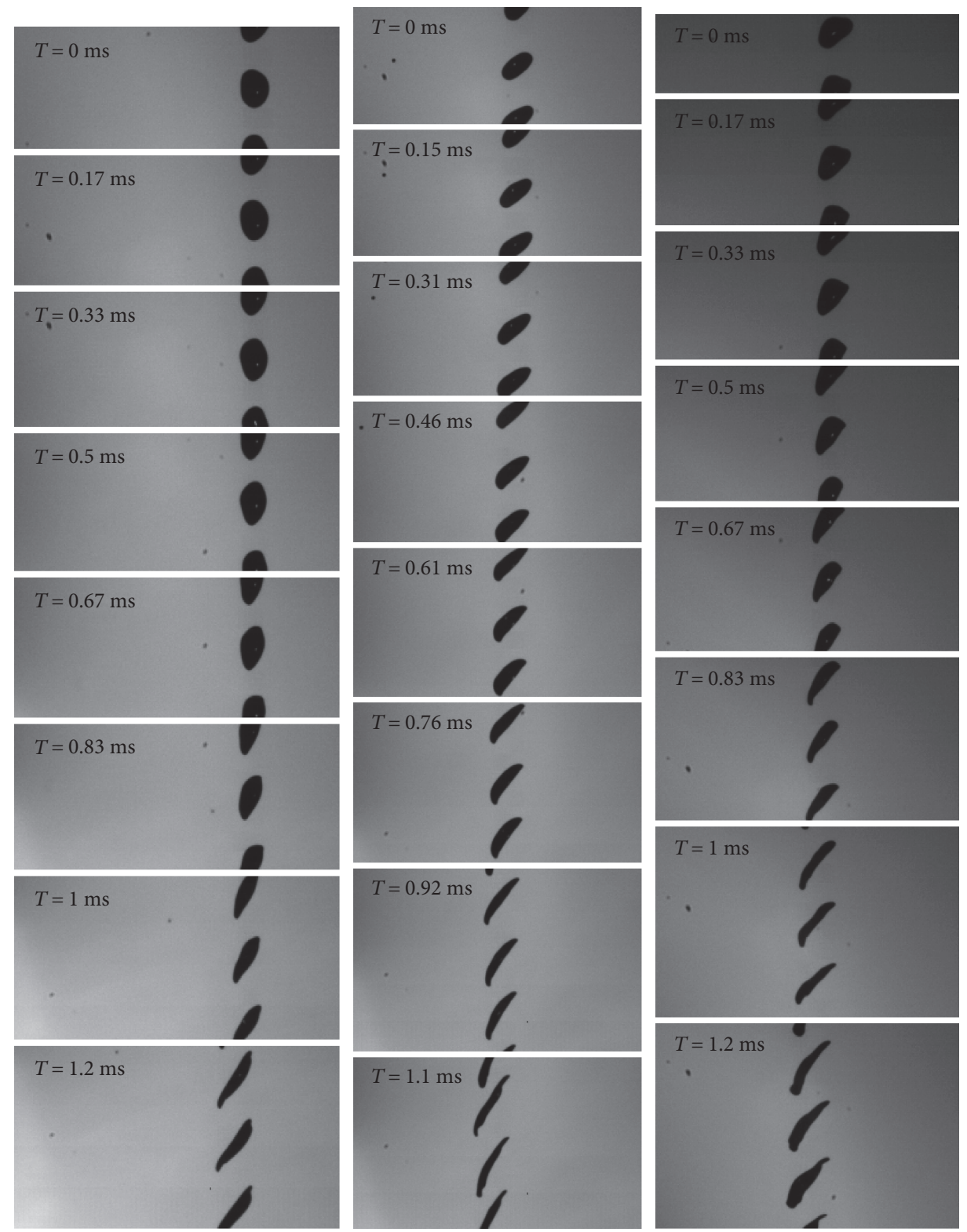

Figure 14: Recorded droplet evolution for cases \#7 (left), \#8 (centre), and \#9 (right).

considered negligible, thereby effectively decoupling the horizontal position equation and the deformation equation. When applying this model to the droplets in the shoulder region, this assumption is no longer valid and the three equations are coupled. Another assumption made in [22] is that droplets deform as an oblate spheroid of maximum half-diameter $a$. It can be observed in Figures 12, 13, and 14 that even though the droplet could be considered an oblate spheroid at a first approach, this is not as obvious as in the stagnation region in the leading edge of the airfoil. Figures 18, 19, and 20 show the comparison of the droplet theoretical trajectories computed with the experimental data for cases 1 to 9 . The numerical trajectories have been computed using the Matlab solver ode15i, which is an implicit differential equation solver. The initial conditions for the computations were taken from the experimental data for each specific test case.
Regarding the actual comparison between measured and computed droplet trajectories, it could be observed in Figures 18, 19, and 20 that the theoretical model provides results with the same level of discrepancy no matter what FOV is considered. In a sense, the previous discussed aerodynamics interference effects may cause the discrepancies observed. However, as argued before, these discrepancies might be somewhat smaller in an actual flying situation.

Finally, it is important to quantify the discrepancies between the measured and computed droplet trajectories. The criterion was to compute for each of the nine cases which studied a figure of merit $\Omega$ defined as the difference (for each time) between the theoretical and experimental " $x / R_{d}$ " divided by the maximum experimental value. The results are shown in Table 3, where it can be observed that the average discrepancy was on the order of $6.4 \%$ at most. This should be compared to the average discrepancy in the 

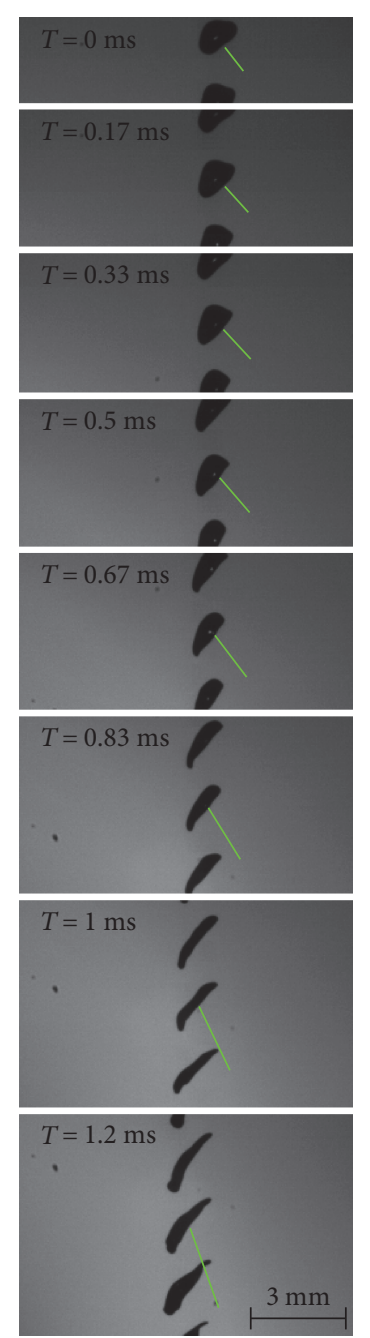

FIGURE 15: Direction of the slip velocity, computed from the experimental results, superimposed on the droplet's train corresponding to case $\# 9$.

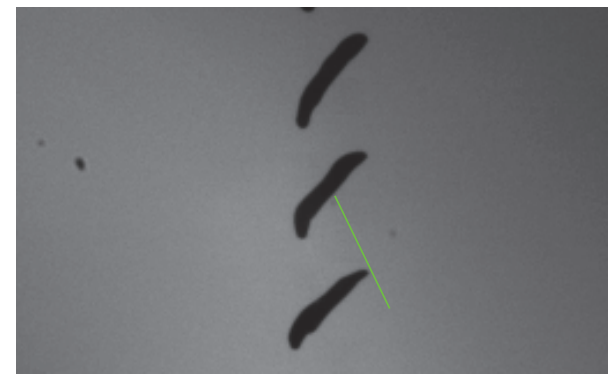

FIGURE 16: Close-up view of the last snapshot of Figure 15 where the aerodynamic shielding of droplets can be observed in detail (the direction of the slip velocity is drawn in green).

stagnation region that was of the order of $3.6 \%$ at most [22]. Then, it could be concluded that model errors in the shoulder region were larger by a factor of 2 than model errors in the stagnation region. However, the larger average errors of $6.4 \%$ could still be considered as acceptable.

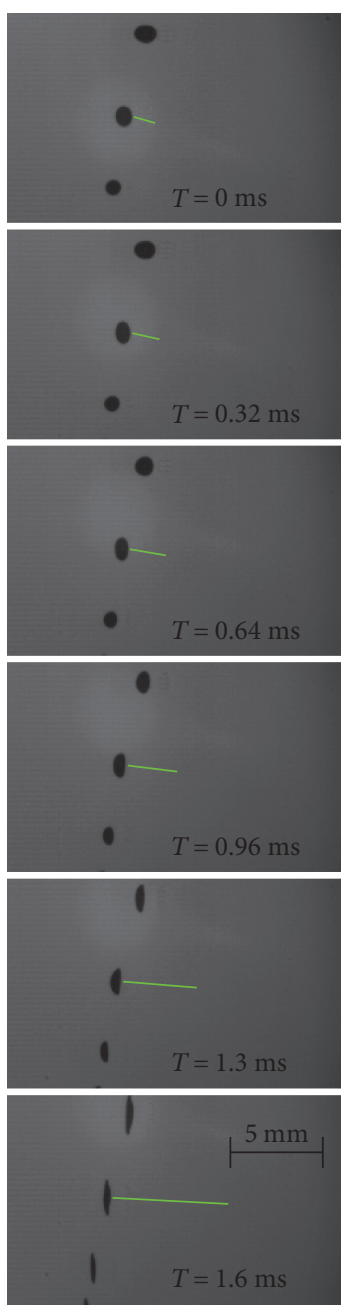

Figure 17: Counterpart of Figure 15 for droplets in the airfoil leading edge region. The slip velocity is superimposed in green color.

\section{Conclusions}

An experimental study has been presented on the subject of water droplet deformation in the vicinity of the shoulder region of an incoming airfoil. Nine different cases have been considered that correspond to three airfoil velocities $(50 \mathrm{~m} / \mathrm{s}$, $70 \mathrm{~m} / \mathrm{s}$, and $90 \mathrm{~m} / \mathrm{s}$ ) and three different fields of vision located close to the shoulder region of the airfoil. Possibly, the most relevant aspect of the results obtained is that, contrary to what happens in the airfoil leading edge region, the droplets moving in the shoulder region tend to tilt significantly towards the direction of the incoming airfoil.

This tilting tends to cause aerodynamics interference between consecutive droplets. The consequence of this type of behavior is that existing droplet trajectory and deformation models that make reasonably accurate predictions in the airfoil leading edge region tend to generate less accurate results when applied to droplets moving in the airfoil shoulder region. However, the LWC of actual heavy rainfall leads to droplet separation distances that are larger than those obtained in the experiment. Then, the question that subsides 


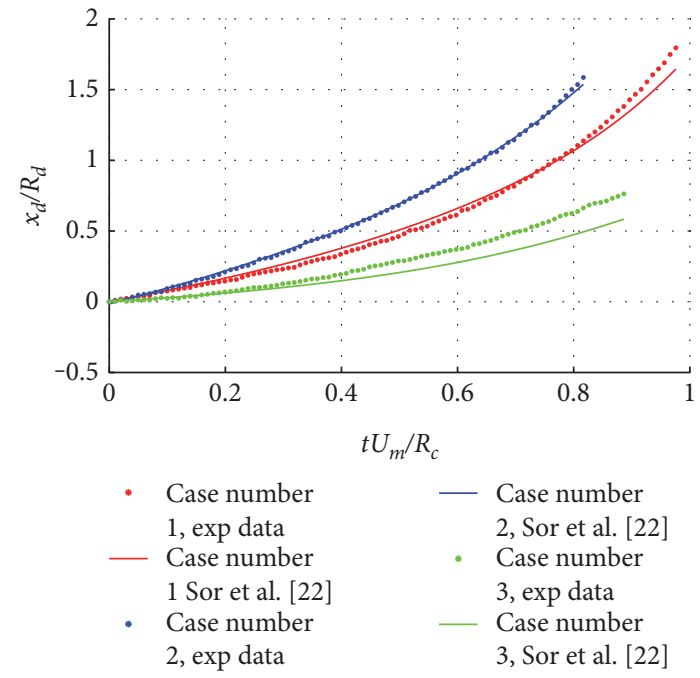

Figure 18: Comparison of the recorded droplet's horizontal position for cases \#1, \#2, and \#3 with those obtained by integrating the theoretical model presented by Sor et al. [22].

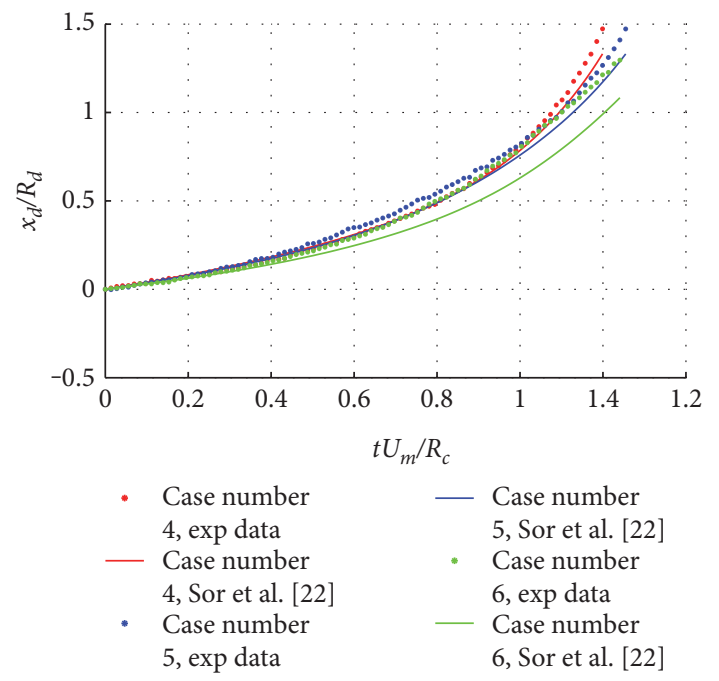

FIgURE 19: Comparison of the recorded droplet's horizontal position for cases \#4, \#5, and \#6 with those obtained by integrating the theoretical model presented by Sor et al. [22].

is whether the theoretical model developed by the authors in a previous work might still be reasonably valid for engineering applications in the shoulder region of an airfoil.

In any case, this issue raises some questions regarding the development of engineering methods and tools for prediction of rainfall effects on aircraft. In particular, two of these questions are as follows: (a) would it be possible, owing to the markedly different types of behavior observed, to develop a single generic model, possible of the population balance equation type, that accounts for droplet deformation and trajectory all around the airfoil? and (b) does it still make sense to develop methods and tools that are based on the behavior of the individual droplets? Then, in this context,

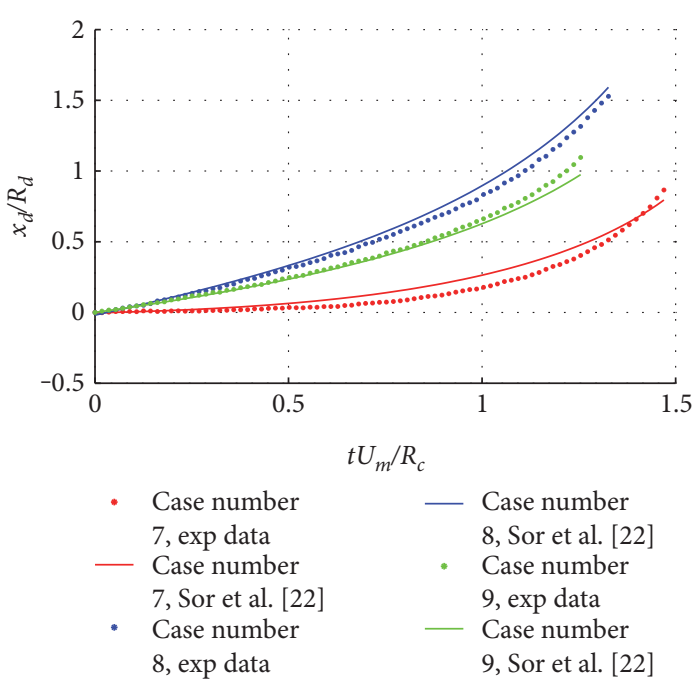

FIgURE 20: Comparison of the recorded droplet's horizontal position for cases $\# 7, \# 8$, and \#9 with those obtained by integrating the theoretical model presented by Sor et al. [22].

TABle 3: Discrepancy between measured and theoretical droplet trajectories for the 9 cases of Table 2 .

\begin{tabular}{lcccc}
\hline Case & FOV \# & $U_{m}(\mathrm{~m} / \mathrm{s})$ & Mean $\Omega(\%)$ & Std $\Omega(\%)$ \\
\hline 1 & 1 & 50 & 2.2 & 2.5 \\
2 & 2 & 50 & 1.7 & 2.4 \\
3 & 3 & 50 & 5.1 & 3.4 \\
4 & 1 & 70 & 1.4 & 1.6 \\
5 & 2 & 70 & 5.5 & 6.1 \\
6 & 3 & 70 & 1.4 & 1.0 \\
7 & 1 & 90 & 6.4 & 4.4 \\
8 & 2 & 90 & 1.7 & 1.1 \\
9 & 3 & 90 & 0.7 & 0.6 \\
\hline
\end{tabular}

the present experimental study could be regarded as an approach that has contributed to pose some questions that might be of interest when addressing the development of future engineering methods and tools in this field.

\section{Nomenclature}

$a$ : Droplet maximum half diameter

c: $\quad$ Model chord

$d$ : Horizontal distance to the model leading edge stagnation point

g: $\quad$ Gravity acceleration

$k$ : $\quad$ Sor et al. [22] model coefficient equal to 9

$m_{d}$ : $\quad$ Droplet mass

$x, x_{d}: \quad$ Horizontal droplet position

$x / c: \quad$ Dimensionless horizontal model coordinates

$y: \quad$ Vertical droplet position

$z / c: \quad$ Dimensionless vertical model coordinates

$t: \quad$ Time 
$\varepsilon: \quad$ Ellipse eccentricity

$\mu_{d}: \quad$ Droplet viscosity

$\rho_{a}: \quad$ Air density

$A_{d}: \quad$ Oblate spheroid surface area

$C_{P}: \quad$ Pressure coefficient (equal to 0.93 , Sor et al. [22])

$C_{D \text { sphere }}$ : Stationary drag coefficient

$C_{D \text { disk }}: \quad$ Stationary drag coefficient

$R_{c}: \quad$ Model leading edge radius

$R_{d}: \quad$ Droplet initial radius

$U: \quad$ Air velocity

$U_{m}: \quad$ Model velocity

$U_{\text {std }}$ : Standard Deviation of the air velocity

$V_{s}: \quad$ Slip velocity

$V_{s x}: \quad$ Horizontal slip velocity

$\mathrm{V}_{s y}: \quad$ Vertical slip velocity

$X: \quad$ Horizontal position in the PIV reference axes

$Z$ : $\quad$ Vertical position in the PIV reference axes.

\section{Conflicts of Interest}

The authors declare that they have no conflicts of interest.

\section{Acknowledgments}

A. Velazquez has been funded by the Spanish Ministry of Economy and Competitiveness (Ministerio de Economia y Competitividad) under Research Contract DPI2016-75296-P and gratefully acknowledges this support. A. GarcíaMagariño was funded by the Spanish Ministry of Defense under the INTA program "Termofluidodinámica". This work is part of the Ph.D. thesis of the first author S. Sor.

\section{References}

[1] T. G. Theofanous, "Aerobreakup of Newtonian and viscoelastic liquids," Annual Review of Fluid Mechanics, vol. 43, pp. 661-690, 2011.

[2] T. G. Theofanous and G. J. Li, "On the physics of aerobreakup," Physics of Fluids, vol. 20, article 052103, 2008.

[3] S. Temkin and H. K. Mehta, "Droplet drag in an accelerating and decelerating flow," Journal of Fluid Mechanics, vol. 116, pp. 297-313, 1982.

[4] O. Igra and K. Takayama, "Shock tube study of the drag coefficient of a sphere in a non-stationary flow," Proceedings of the Royal Society A: Mathematical, Physical and Engineering Sciences, vol. 442, pp. 231-247, 1993.

[5] G. Jourdan, L. Houas, O. Igra, J. L. Estivalezes, C. Devals, and E. E. Meshkov, "Drag coefficient of a sphere in a nonstationary flow: new results," Proceedings of the Royal Society A: Mathematical, Physical and Engineering Sciences, vol. 463, pp. 3323-3345, 2007.

[6] C. Chang, X. Deng, and T. G. Theofanous, "Direct numerical simulation of interfacial instabilities: a consistent, conservative, all-speed, sharp-interface method," Journal of Computational Physics, vol. 242, pp. 946-990, 2013.

[7] T. C. Rendall and C. B. Allen, "Finite-volume droplet trajectories for icing simulation," International Journal of Multiphase Flow, vol. 58, pp. 185-194, 2014.

[8] S. K. Jung and R. S. Myong, "A second-order positivitypreserving finite volume upwind scheme for air-mixed droplet flow in atmospheric icing," Computers \& Fluids, vol. 86, pp. 459-469, 2013.

[9] E. Iuliano, G. Mingione, F. Petrosino, and F. Hervy, "Eulerian modeling of large droplet physics toward realistic aircraft icing simulation," Journal of Aircraft, vol. 48, pp. 1621-1632, 2011.

[10] Y. Cao, Z. Wu, and Z. Xu, "Effects of rainfall on aircraft aerodynamic," Progress in Aerospace Sciences, vol. 71, pp. 85-127, 2014.

[11] J. Krezel, W. McNichols, and J. Prete, "Causality analysis for aviation weather hazards," in AIAA 2008-8914. 26th Congress of the International Council of Aeronautical Sciences (ICAS), pp. 1-10, Anchorage, 2008.

[12] R. J. Hansman and A. P. Craig, "Low Reynolds number tests of NACA 64-210 NACA 0012 and Worthmann FX67-K170 airfoils in rain," Journal of Aircraft, vol. 24, pp. 559-566, 1987.

[13] R. Zhang and Y. Cao, "Study of aerodynamics characteristics on an airfoil in rain," Journal of Aerospace Power, vol. 25, pp. 2064-2069, 2010.

[14] A. Rehorst, J. Chung, and K. M. Potapezu, "Study of icing effects on performance and controllability of an accident aircraft," Journal of Aircraft, vol. 37, pp. 253-259, 2000.

[15] A. Lampton and J. Valasek, "Prediction of icing effects on the lateral/directional stability and control of light airplanes," Aerospace Science and Technology, vol. 23, pp. 305-311, 2012.

[16] P. R. Thomas, B. Kurt, and R. Willian, Iced Aircraft Flight Data for Flight Simulator Validation, NASA Center for Aerospace Information, Hanover, MD, USA, 2003, NASA TM/2003-212114.

[17] J. C. Lasheras, C. Eastwood, C. Martínez-Bazán, and J. L. Montañés, "A review of statistical models for the break-up of an immiscible fluid immersed into a fully developed turbulent flow," International Journal of Multiphase Flow, vol. 28, pp. 247-278, 2002.

[18] S. Maab and M. Kraume, "Determination of breakage rates using single drop experiments," Chemical Engineering Science, vol. 70, pp. 146-164, 2012.

[19] Z. Wu and Y. Cao, "Dynamics of initial drop splashing on a dry smooth surface," PLoS One, vol. 12, no. 5, article e0177390, 2017.

[20] A. García-Magariño, S. Sor, and A. Velazquez, "Experimental characterization of water droplet deformation and breakup in the vicinity of a moving airfoil," Aerospace Science and Technology, vol. 45, pp. 490-500, 2015.

[21] A. García-Magariño, S. Sor, and A. Velazquez, "Data reduction method for droplet deformation experiments based on high order singular value decomposition," Experimental Thermal and Fluid Science, vol. 79, no. 2016, pp. 13-24, 2015.

[22] S. Sor, A. García-Magariño, and A. Velázquez, "Model to predict water droplet trajectories in the flow past an airfoil," Aerospace Science and Technology, vol. 58, pp. 26-35, 2016. 


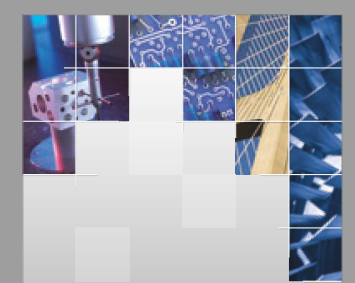

\section{Enfincering}
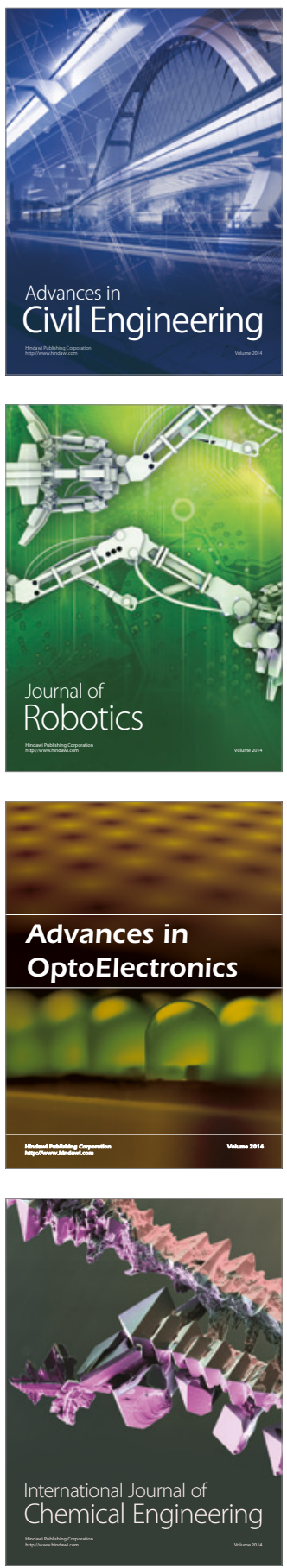

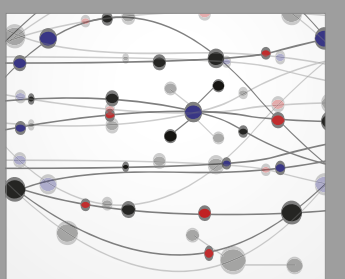

The Scientific World Journal

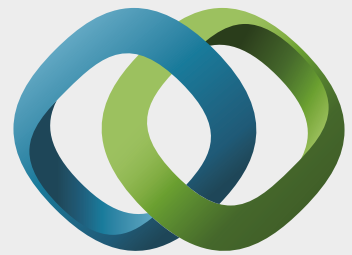

\section{Hindawi}

Submit your manuscripts at

https://www.hindawi.com
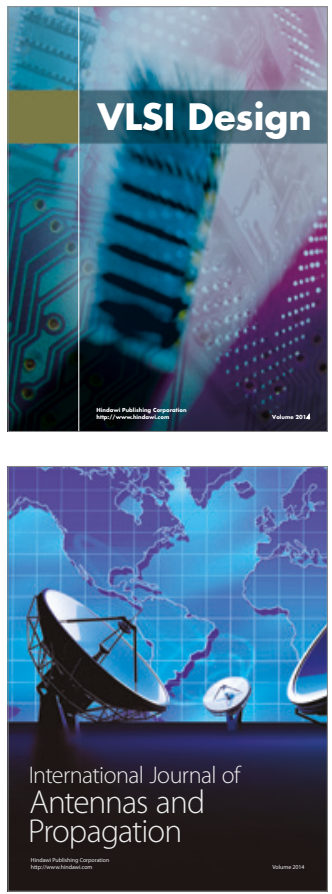

\section{Rotating}

Machinery
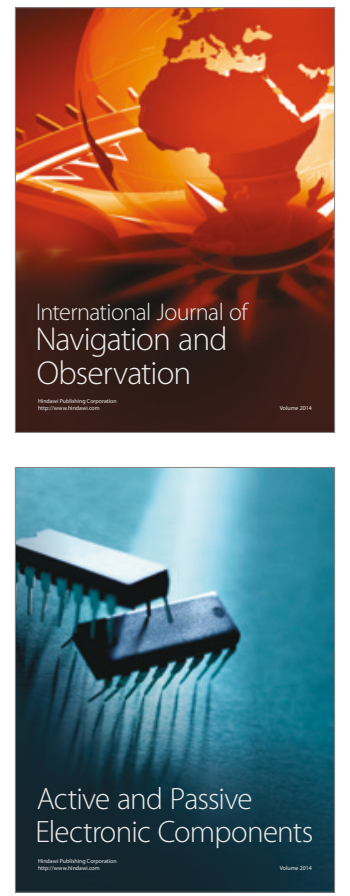
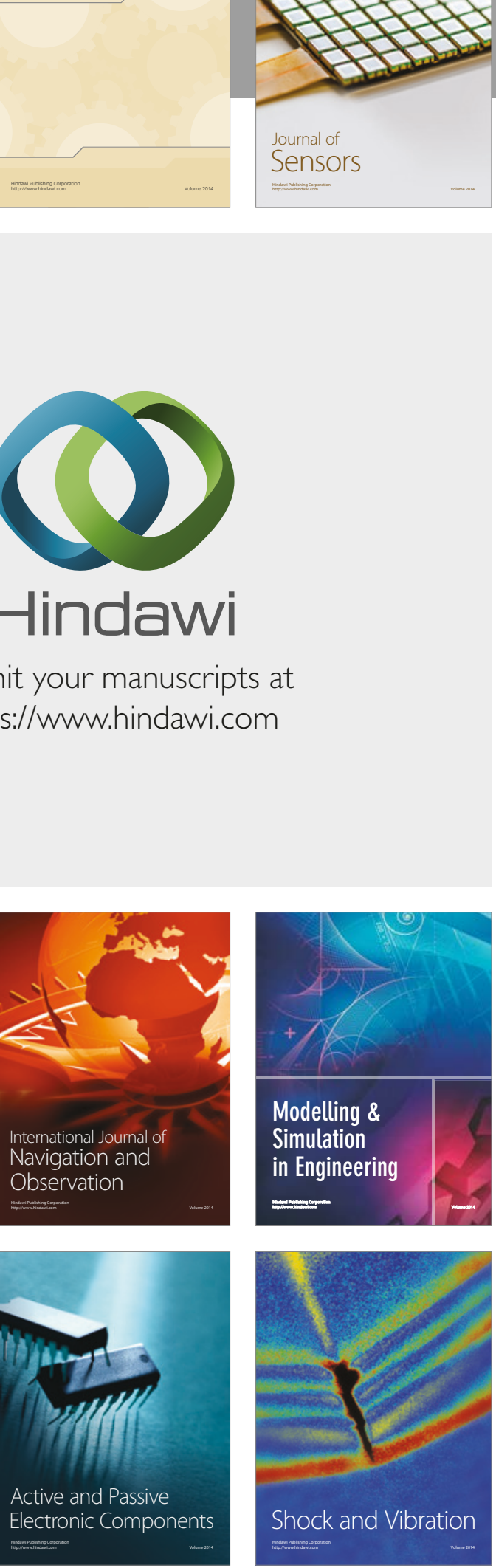
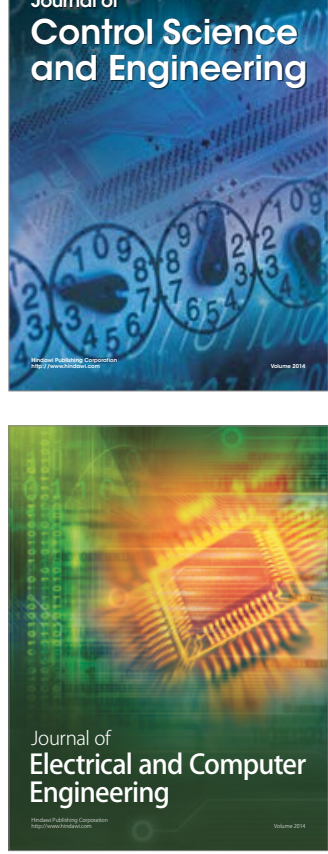

Distributed

Journal of

Control Science

and Engineering
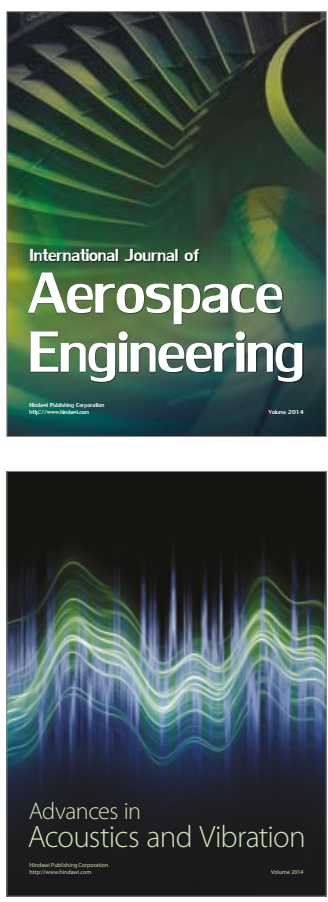

Sensor Networks 